Bull. Mater. Sci., Vol. 6, No. 2, May 1984, pp. 165-175. (C) Printed in India.

\title{
Electrochemical preparation of potassium gold cyanide
}

\author{
INDIRA RAJAGOPAL and S R RAJAGOPALAN \\ Materials Science Division, National Aeronautical Laboratory, Bangalore 560017, India \\ Abstract. The essential requirements for the industrial preparation of potassium gold \\ cyanide (PGC) are: (a) high rate of dissolution and (b) smooth and uniform dissolution. \\ Employing galvanostatic and potentiostatic polarisation data and observations on the surface \\ topography of anodes dissolved by both the techniques, it is shown that potentiostatic \\ dissolution of gold in potassium cyanide at $+0.345 \mathrm{~V}$ satisfies the above requirements.
}

Keywords. Electrochemical preparation; anodic dissolution; gold plating salt; plating; potassium gold cyanide.

\section{Introduction}

Electroplated coatings of gold are characterised by high conductivity, excellent resistance to corrosion, low contact resistance, and remarkable ability to form very good thermocompression bonds. Because of these properties electroplated gold coatings are extensively used in electronics and aerospace industries. These properties have their maximum value when the purity of deposited gold is highest, which in turn depends on the purity of the gold salt used in the preparation of the bath. Be it an acid, neutral phosphate, citrate or alkaline cyanide gold plating bath, potassium gold cyanide (PGC) is the starting material. It is therefore important that PGC used for preparing plating baths must be very pure.

There are two methods of preparing PGC namely, chemical and electrochemical. In the chemical method, gold is dissolved in aquaregia and is precipitated as fulminate by neutralising the solution with ammonia (Blum and Hogaboom 1958). There are a number of problems with this method. The fulminate should always be kept wet to prevent it from exploding. The yield of PGC depends critically on the conditions of precipitation. Under the best conditions the yield is $95 \%$ (Blum and Hogaboom 1958).

Even though the loss is only $5^{\circ}$, it is significant because of the high cost of gold. The purity of the salt prepared chemically will depend on the purity of gold used as a starting material. Besides it will invariably contain certain amount of chloride as an impurity. This is not desirable in the plating bath since it causes the dissolution of stainless steel anodes and thereby contaminates the bath with iron which is a deleterious impurity (Fischer and Weimer 1964; Graham Silver 1969). During the conversion of $\mathrm{AuCl}_{3}$ to $\mathrm{PGC}$ by reaction with cyanide only auricyanide $\left(\mathrm{Au}(\mathrm{CN})_{4}^{-}\right)$is formed which gets reduced to aurocyanide $\left(\mathrm{Au}(\mathrm{CN})_{2}\right)$ slowly or rapidly, depending on the conditions of plating (Britton and Dodd 1949; Foulke 1974). Thus a plating bath made from chemically prepared PGC will contain both mono and trivalent gold in solution. Their ratio will keep changing with the age of the bath, thereby making it difficult to judge the time needed to deposit a certain thickness. Thus it is seen that the 
chemical method is laborious, needs the skill of a trained person and yields a plating solution which contains undesirable chloride and auricyanide.

The electrochemical method depends on the direct anodic dissolution of gold in cyanide solution (Blum and Hogaboom 1958; Visco 1974). Excepting for the description of a practical procedure for preparing PGC - by dissolving gold at constant current (Natarajan and Lalitha 1970)- no detailed study of this method appears to have been made.

The electrochemical method, though simple has its own problems. Gold exhibits passivity in cyanide solution at a relatively low current density $(\mathrm{CD})$. Hence the anodic dissolution has to be carried out at a very low $\mathrm{CD}$. The consequent disadvantages are: (a) the process is slow (b) it results in loss of gold due to disintegration of the anode resulting from the etching type of dissolution that takes place at very low $\mathrm{CD} / \mathrm{s}$. Even though usable $\mathrm{CD}$ for dissolution can be increased by (a) vigorous stirring (b) using rotating anode and (c) using forced circulation, the dissolution will still be of the etching type. Besides, these methods of enhancing the rate are accompanied by the risk of loss of expensive gold solution by spillage and spray.

It has been demonstrated that alloying of gold with thallium or addition of thallium to the electrolyte can prevent the gold becoming passive during its anodic dissolution in cyanide solution (Cathro and Koch 1964). This method would not be acceptable for the preparation of plating grade PGC because it would introduce thallium impurity in PGC. Thallium is an objectionable impurity in gold plating solution since it causes poor bonding of electrodeposited gold (Joshi and Stein 1972; Joshi et al 1975).

If the electrochemical method is to be useful for the industrial preparation of PGC it must satisfy the following requirements: (a) the rate of anodic dissolution must be large; (b) the dissolution must be smooth and uniform; (c) it must be similar to electropolishing.

Even thougl the anodic behaviour of gold in cyanide solution has been investigated off and on during the last three decades, no systematic study for its use in the preparation of PGC has been reported. In recent times, many workers (Kirk et al 1978; Pan and Van 1979; Kirk and Foulkes 1980; Kirk et al 1980; Thurgood et al 1981) have investigated the mechanism of anodic dissolution of gold in aqueous cyanide solution. These studies have thrown light on the mechanism of anodic dissolution. Information on the morphological characteristic of gold dissolved anodically under different conditions is not available in the literature. This is essential for arriving at conditions suitable for the electrochemical preparation of PGC. Hence we have investigated the nature of the surface that results from the anodic dissolution of gold under different conditions and the results are presented here. From this study, the conditions for the electrolytic preparation of $\mathrm{PGC}$ have been derived and the same are also presented.

\section{Experimental}

A H-type cell with a sintered glass-disc fused in the centre of the horizontal limb of the $\mathrm{H}$-cell to prevent the mixing of the catholyte and anolyte was used. The cathode was a platinum wire wound as a coil. Gold was rolled as a sheet and used as an anode. A microelectrode was used as anode for measurement with a bridge filled with KCN solution of the same concentration $(4 \%)$ as that of the anolyte and terminating in a 
luggin capillary was used to measure the potentials. The luggin tip was placed close to the anode to minimise iR drop. The $I-E$ curves under galvanostatic and potentiostatic polarisation were measured with standard experimental set-up.

Before each experiment the anode was cathodically cleaned in a $10 \% \mathrm{NaOH}$ solution at a $\mathrm{CD}$ of $0.2 \mathrm{~A} / \mathrm{cm}^{2}$ for $1 \mathrm{~min}$, rinsed in distilled water, dried and weighed. The anode was weighed after the experiment to determine the rate of dissolution for measuring current efficiency. The number of coulombs were calculated by integrating current time curves.

Experiments on the preparation of PGC were carried out using the H-type cell described above and employing gold foil of area $4 \mathrm{~cm}^{2}$ as anode. Ultrasonic agitation was done using vibronics ultrasonics tank (Vibronic model VPL-P1) at an intensity of $0.3 \mathrm{~W} / \mathrm{cm}^{2}$. All solutions were prepared from Analar $\mathrm{KCN}$.

\section{Results and discussion}

Galvanostatic anodic $1-E$ curves for gold in $40 \mathrm{~g} / \mathrm{KCN}$ solution after dissolving gold for different intervals of time at a $C D$ of $10 \mathrm{~mA} / \mathrm{cm}^{2}$ are given in figure 1 . In all the polarisation curves, it is seen that anodic dissolution starts at a very negative potential, the actual value being dependent on the electrolyte composition. At potentials more negative to $-0.6 \mathrm{~V}$, the current efficiency for dissolution is more than $100 \%$. This is because at such potentials the dissolution of gold proceeds by chemical and electrochemical processes. The plateau in the $I-E$ curve can be taken to represent approximately the limiting $\mathrm{CD}$ for dissolution of gold. It progressively decreases with increasing time of electrolysis because free cyanide concentration decreases and that of PGC increases with increased times of electrolysis. If this interpretation is correct, one would expect an enhancement of $\mathrm{CD}$ corresponding to the plateau in stirred solutions. The effect of ultrasonic (Us) agitation is shown in figure 2. A two-fold increase in the limiting $C D$ is noticed, which lends support to the view that the plateau is caused by diffusion limitation.

Photomicrographs of gold galvanostatically dissolved in KCN solution at various $\mathrm{CD} / \mathrm{s}$ are given in figures 3 to 6 and using the data on current efficiency (table 1), $I-E$ curves and observation of the surface under microscope, the following inferences can be made. At low $\mathrm{CD}$ (the region A-B in figure 1) gold is dissolved by crystallographicallycontrolled etching. Facets of grains and grain boundaries are clearly seen (figures 3,4).

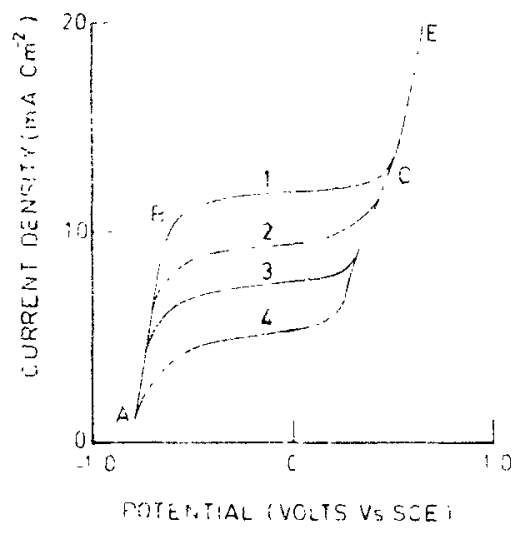

Figure 1. Galvanostatic anodic $I-E$ curve for gold in KCN solution into which gold is dissolved for different intervals of time. Concentration of $\mathrm{KCN}$ (in gpl) and $\mathrm{KAu}(\mathrm{CN})_{2}$ respectively 1. 40.0; 2 . After 1 hr of electrolysis at $10 \mathrm{~mA} / \mathrm{cm}^{2} \cdot 35 \cdot 7,9 \cdot 60 ; 3$. After $2 \mathrm{hr}$ of electrolysis at $10 \mathrm{~mA} / \mathrm{cm}^{2} .31 \cdot 4,19 \cdot 4 ; 4$. After $3 \mathrm{hr}$ of electrolysis at $10 \mathrm{~mA} / \mathrm{cm}^{2} .27 \cdot 1,28 \cdot 9 \mathrm{gpl}$. 


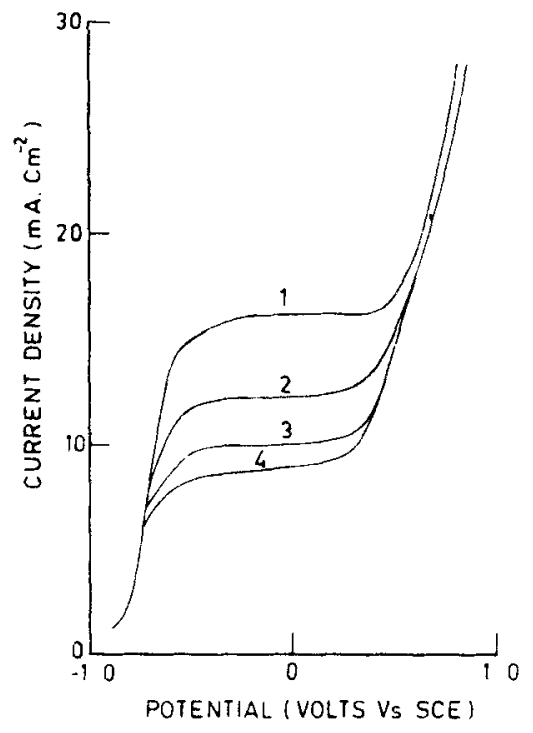

Figure 2. Galvanostatic anodic $I-E$ curve for gold in $\mathrm{KCN}$ in the presence of us stirring. The other conditions are same as for figure 1.

The surface of the anode dissolved at BC corresponding to the plateau region, (figure 5) does not show grain boundary delineation and is smooth. In this region, the dissolution of the metal must be occurring through pores present randomly in the film; which being soluble in the electrolyte must be getting continually renewed. Hence the dissolution is similar to electropolishing. In the region, $\mathrm{CE}$, the current rises rapidly because of oxygen evolution. The anode surface, under these conditions, is seen to be covered with a brownish film, which is probably the polymeric HCN film. The current efficiency progressively decreases with $\mathrm{CD}$ in this region because the anode is passive. Under these conditions the anode surface is seen to be pitted (figure 6).

From the point of view of preparation of $\mathrm{PGC}$, the best condition is that corresponding to the plateau. In practice, it will not be possible to keep the anode in the plateau region for the entire period of the galvanostatic preparation of PGC for the following reasons: (a) The plateau region is an unstable region. (b) The CD corresponding to the plateau region progressively decreases with increased times of electrolysis (curves 2,3,4 in figure 1). Hence if galvanostatic dissolution is employed, to start with the anode can be made to dissolve in the plateau region, but very soon, it will be

Table 1. Data on current efficiency for the galvanostatic dissolution of gold in $\mathbf{4 0}$ gpl solution of $\mathrm{KCN}$ at $30^{\circ} \mathrm{C}$.

\begin{tabular}{lcl}
\hline $\begin{array}{c}\mathrm{CD} \\
\left(\mathrm{mA} / \mathrm{cm}^{2}\right)\end{array}$ & $\begin{array}{c}\mathrm{t} \\
(\mathrm{min})\end{array}$ & $\begin{array}{c}\mathrm{CE} \\
\left(\begin{array}{c}0 \\
\vdots\end{array}\right)\end{array}$ \\
\hline 1 & 125 & $110 \pm 3$ \\
$2 \cdot 5$ & 50 & $102 \pm 3$ \\
5 & 25 & $100 \pm 2$ \\
$7 \cdot 5$ & 14 & $100 \pm 2$ \\
10 & 12.5 & $100 \pm 2$ \\
15 & 8 & 90 \\
20 & 6 & 70 \\
\hline
\end{tabular}



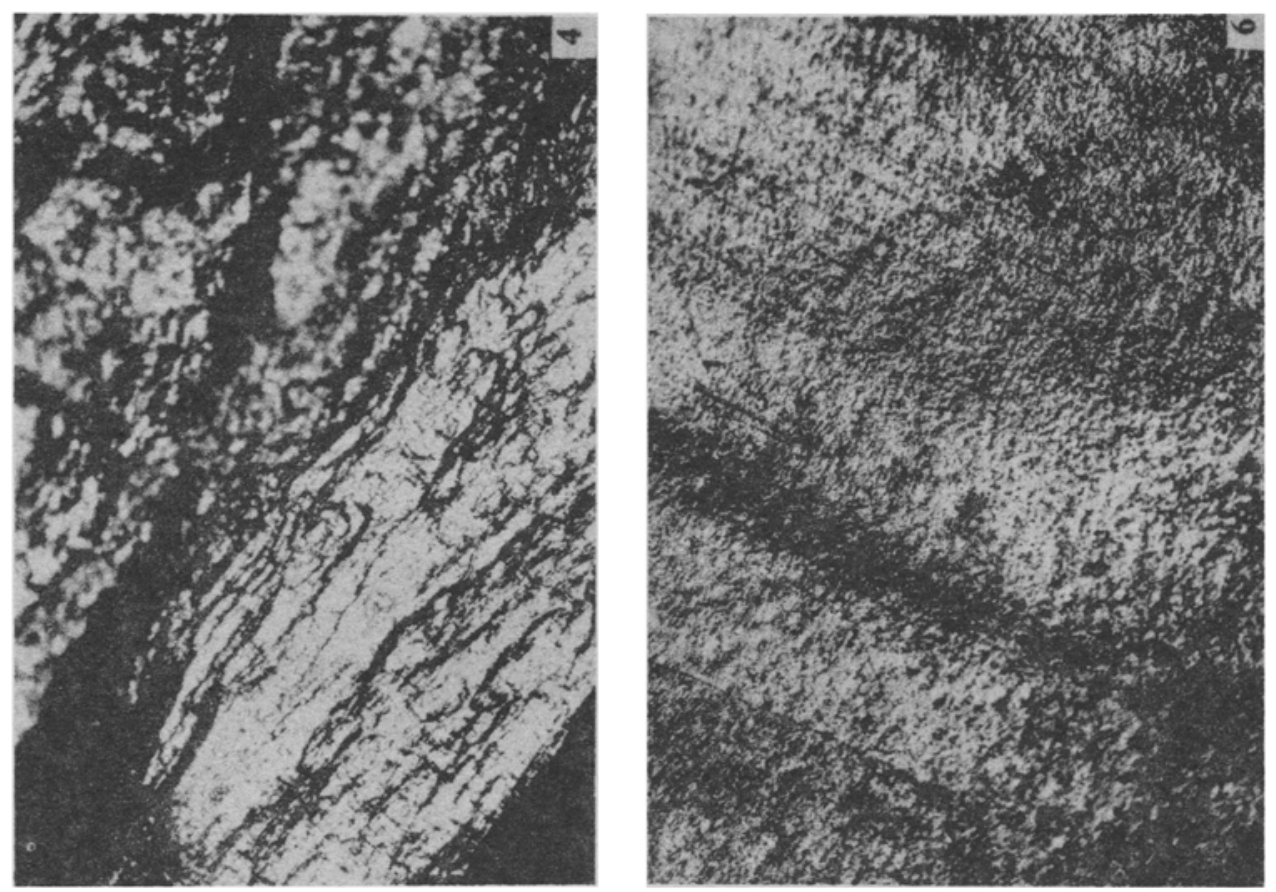

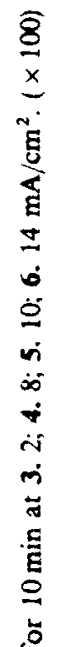
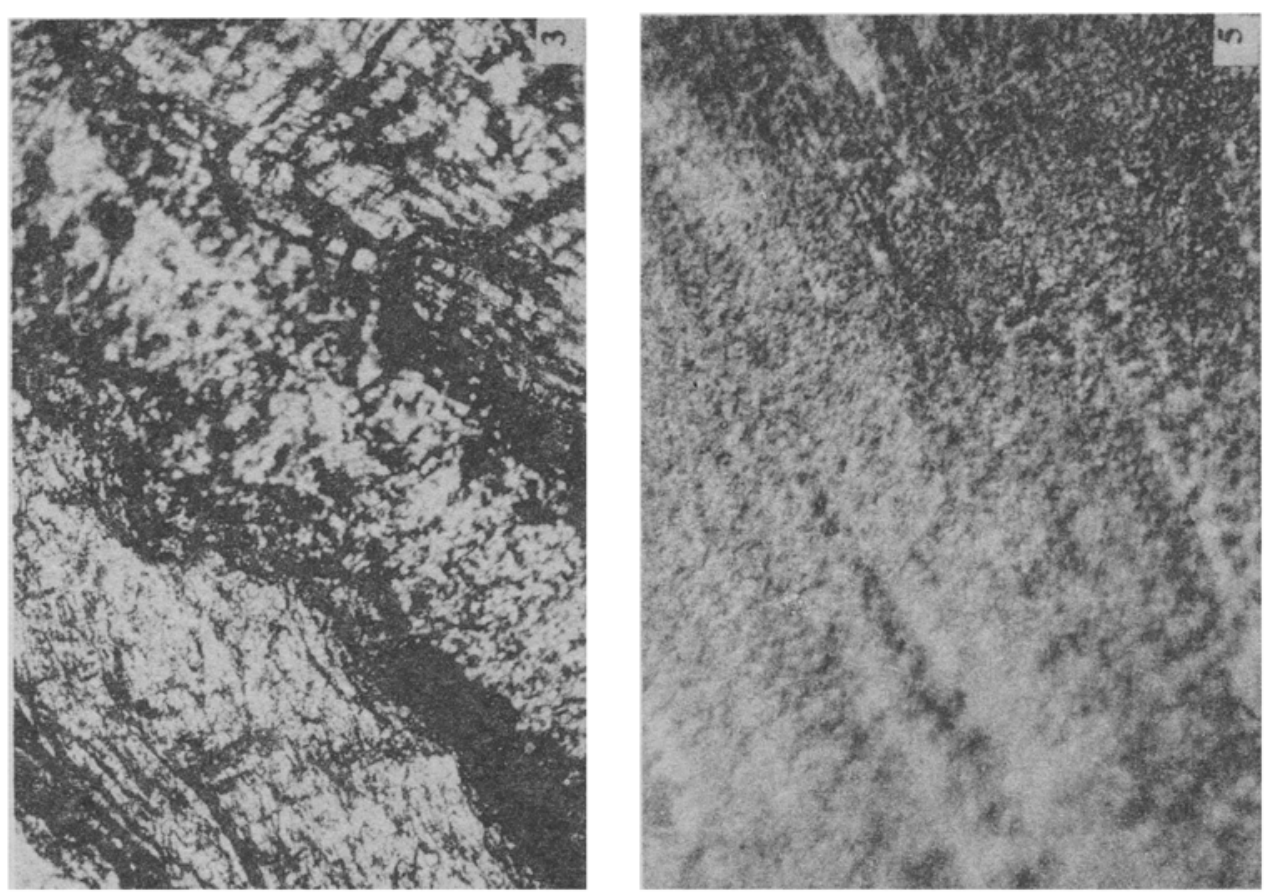

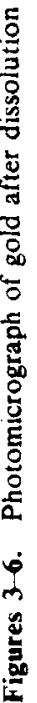




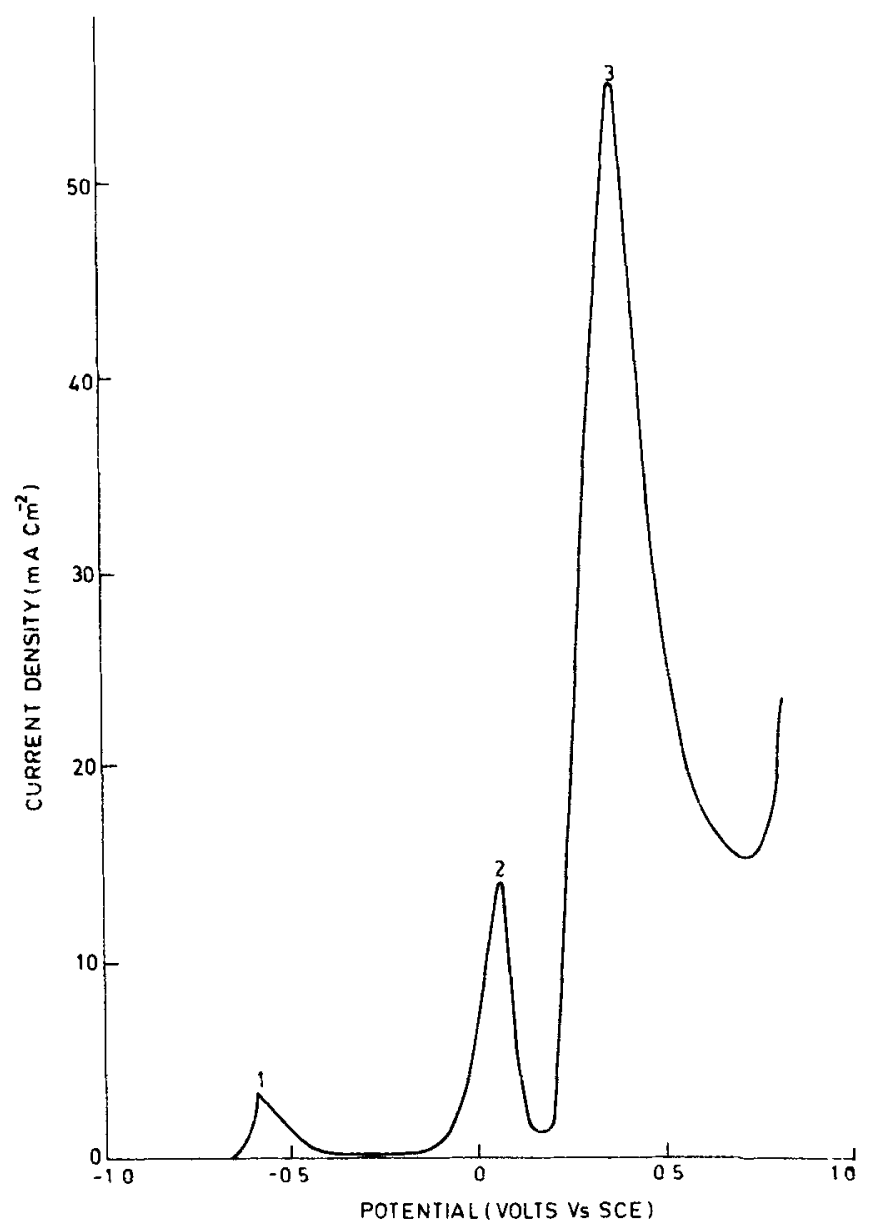

Figure 7. Potentiostatic anodic $I-E$ curve for gold dissolution in $40 \mathrm{gpl} \mathrm{KCN}$ solution.

dissolving in the region $\mathrm{CE}$. This is because, the limiting $\mathrm{CD}$ gets lowered as the concentration of $\mathrm{KCN}$ decreases. If the anode is to be dissolved in the plateau region throughout the preparative run, the anode $C D$ must be decreased in a programmed manner, which is not practical. Hence in practice for galvanostatic preparation of PGC one has to employ only a very low $\mathrm{CD}$ falling in the region $\mathrm{AB}$ and has to accept the concommitant disadvantages of low rate of production and loss of gold due to disintegration of the anode towards the end of its dissolution.

A comparison of the galvanostatic and potentiostatic polarisation curve (figure 7) reveals that the potential of the second and the third peak is in the plateau region of the galvanostatic polarisation curve.

Using the observation of Kirk et al (1979) that gold dissolves in potassium cyanide in the monovalent state at potentials less than $+0.4 \mathrm{~V}(\mathrm{SCE})$ and the current efficiency data presented here, it is concluded that gold dissolves as aurocyanide at potentials corresponding to second and third peak. Greater than $100 \%$ current efficiency observed at $-0.6 \mathrm{~V}$ is probably due to the additional chemical dissolution. Similar behaviour was found in the galvanostatic dissolution. 
Table 2. Data on current efficiency for the potentiostatic dissolution of gold in $40 \mathrm{gpl}$ solution of $\mathrm{KCN}$ at $30^{\circ} \mathrm{C}$.

\begin{tabular}{ccc}
\hline $\begin{array}{c}\text { Anode } \\
\text { potential } \\
\text { is SCE } \\
\text { (V) }\end{array}$ & $\begin{array}{c}t \\
(\mathrm{~min})\end{array}$ & $\begin{array}{c}\mathrm{CE} \\
\left({ }^{\circ}\right)\end{array}$ \\
\hline-0.4 & 120 & $110 \pm 2$ \\
+0.5 & 60 & $102 \pm 2$ \\
+0.35 & 30 & $100 \pm 2$ \\
+0.75 & 60 & $90 \pm 2$ \\
+0.85 & 30 & $80 \pm 5$ \\
\hline
\end{tabular}

At a potential of $-0.6 \mathrm{~V}$ gold appears to be undergoing etching type of dissolution (figure 8). The surface of the anode dissolved at $+0.02 \mathrm{~V}$ appears relatively smooth and shows appreciable grain boundary attack (figure 9). Probably the dissolution is partly of the electropolishing type and partly of the crystallographic etching type. Kirk et al (1980) have ascribed the peak at $+0.02 \mathrm{~V}$ to the formation of $\mathrm{Au}(\mathrm{OH})$ film which is not easily soluble in the electrolyte--hence the absence of electropolishing type dissolution.

The surface of the anode dissolved at the potential of $+0.345 \mathrm{~V}$ (corresponding to the third peak) appears very smooth, bright and does not show grain boundary attack figure 10. No disintegration of the metal was noticed till the last trace of it was dissolved. The third peak was ascribed to the passivation by $\mathrm{Au}_{2} \mathrm{O}_{3}$ (MacArthur 1972; Cathro and Koch 1964) and to $\mathrm{Au}(\mathrm{OH})_{3}$ (Pan and Wan 1979). Both $\mathrm{Au}_{2} \mathrm{O}_{3}$ and $\mathrm{Au}(\mathrm{OH})_{3}$ can dissolve in cyanide solution and hence can result in electropolishing by the mechanism suggested by Hickling and Higgins (1956) and Hoar and Mowat (1950). Cathro and Koch (1964) found by reflectivity measurements an enhancement of reflectivity in the region of the third peak. These observations published in the literature and our observations on the microstructure of the anode polarised to $+0.345 \mathrm{~V}$ compel us to conclude that at peak 3 , an electropolishing type dissolution occurs. Even though the passive film at peak 3 contains trivalent gold, gold still dissolves only in the monovalent state (See current efficiency data in table 2.). This has been pointed out by Pan and Van (1979) and Kirk et al (1979). Our current efficiency data also confirm this.

If the passive layer causing the anodic peak is capable of dissolving in the electrolyte, one would expect the $\mathrm{CD}$ corresponding to the peak to increase with stirring. In figure 11 the effect of ultrasonic stirring on the potentiostatic polarisation curve for gold dissolution in a solution containing $28 \mathrm{gpl}$ of $\mathrm{KAu}(\mathrm{CN})_{2}$ and $29 \mathrm{gpl}$ of $\mathrm{KCN}$ is shown. It is seen that ultrasonic stirring increases the peak $\mathrm{CD}$ thereby proving that the passive layer is soluble in the electrolyte. From the above discussion it is clear that potentiostatic dissolution of gold at $+0.345 \mathrm{~V}$ (vS SCE) can be used for the electrochemical preparation of PGC. In our laboratory this method has been used quite successfully. The PGC prepared by this method is shown to be very pure by emission spectrographic examination. Without using ultrasonic stirring this method is 10 times faster than the galvanostatic dissolution method.

By this method gold foil can be dissolved almost completely without the foil getting necked at the solution air interface (figure 12) and subsequently getting detached at the necked region. Such necking and detachment takes place in galvanostatic dissolution 

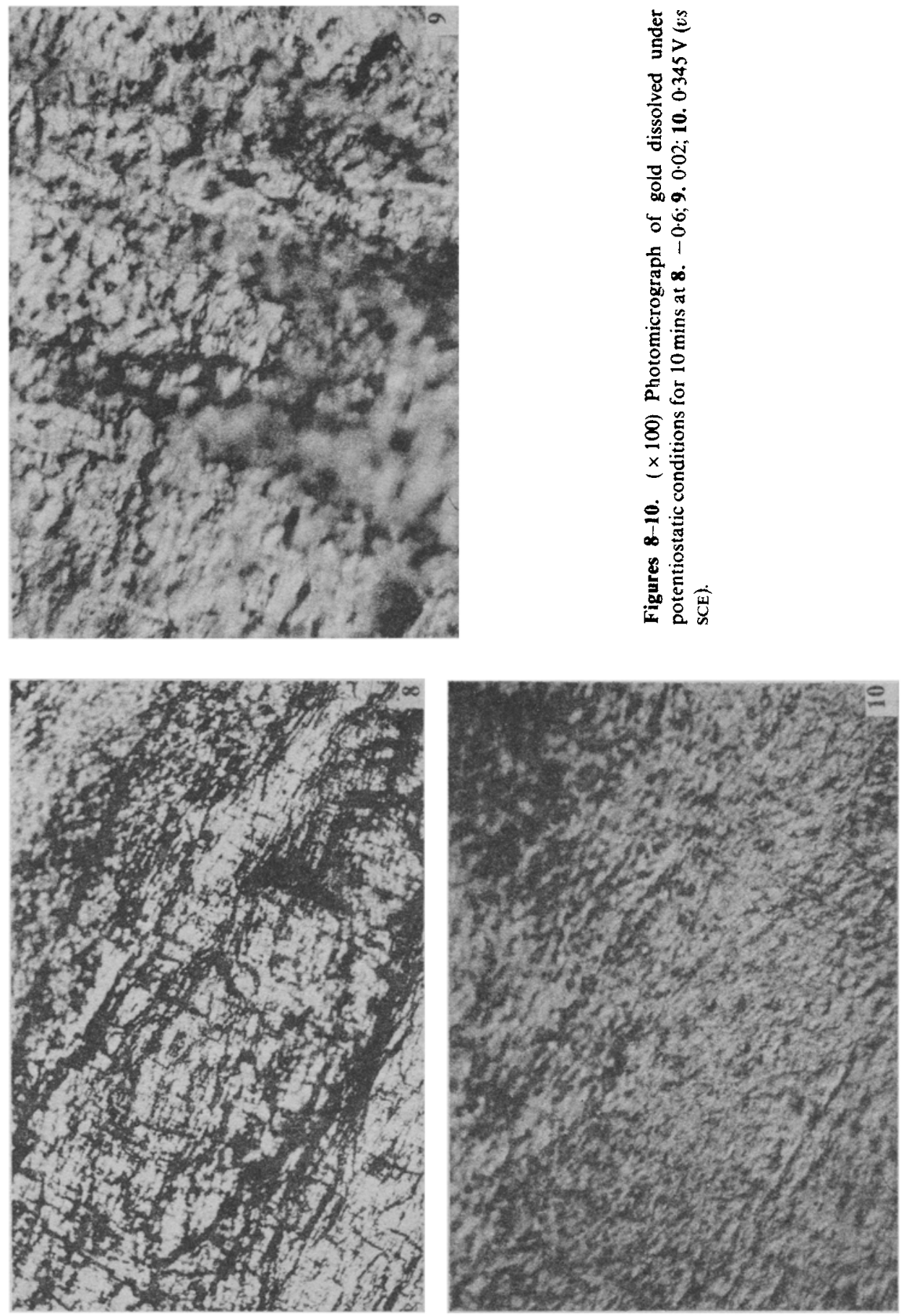


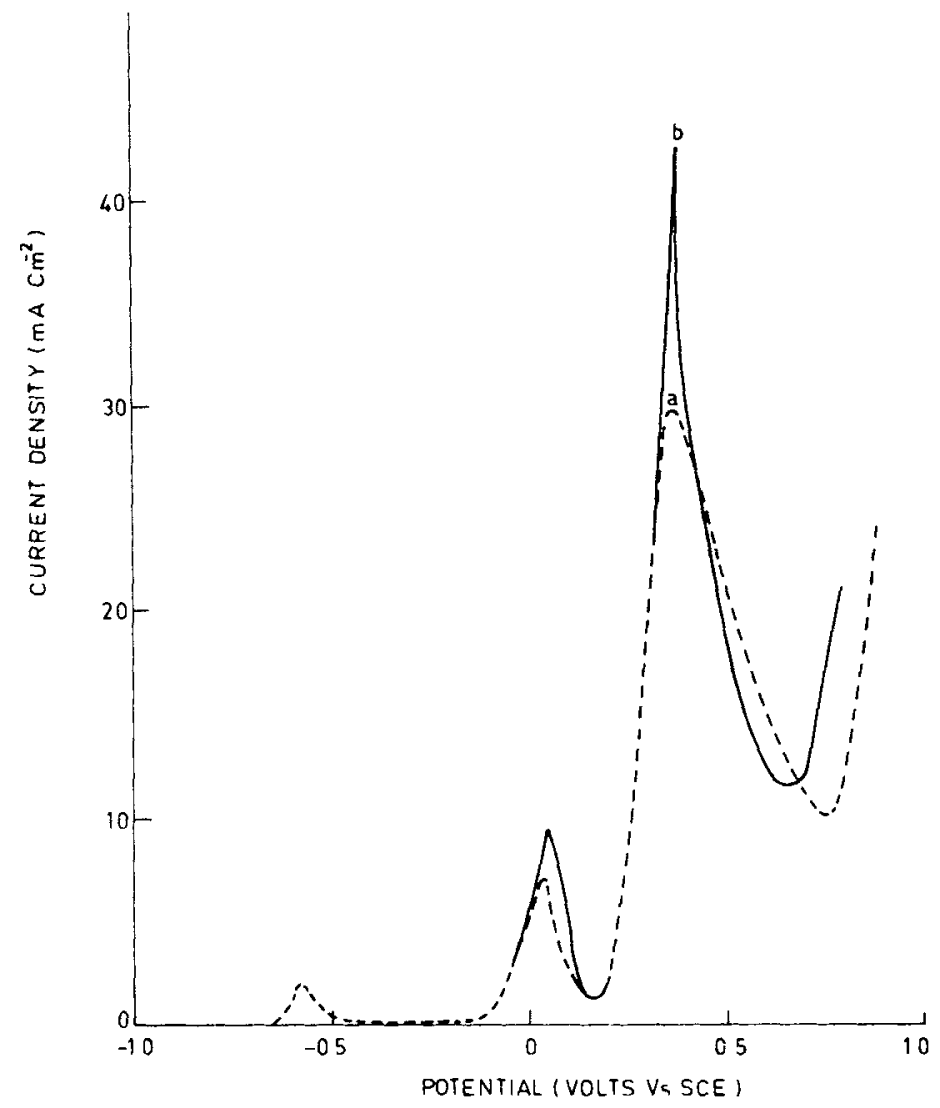

Figure 11. Potentiostatic anodic $I-E$ curve for gold in $\mathrm{KCN}$ solution after $2 \mathrm{hr}$ of dissolution (a) without US and (b) with US agitation.

(figure 13). Further this process helps to dissolve the gold foil very uniformly without disintegration from the start to finish (figures 14, 15).

In order to give an idea of the time needed for preparation of PGC the following data from our experience is given. $10 \mathrm{~g}$ of gold was rolled into a foil $12 \mathrm{~cm}$ long and $2 \mathrm{~cm}$ wide. This was dissolved in $200 \mathrm{ml}$ of $40 \mathrm{gpl}$ potassium cyanide solution potentiostatically at $+0.345 \mathrm{~V}$ (vS SCE). In $1 \mathrm{hr}$ the foil was completely dissolved.

\section{Conclusions}

Plating grade PGC can be prepared conveniently by the potentiostatic dissolution of gold in KCN solution at $+0.345 \mathrm{~V}$ (vS SCE). This method is at least 10 times faster than the galvanostatic method. The rate of dissolution by this method can be enhanced by using ultrasonic stirring. The PGC produced by this method is free from chloride and auricyanide. In this method there is no loss of gold due to disintegration of the anode. 

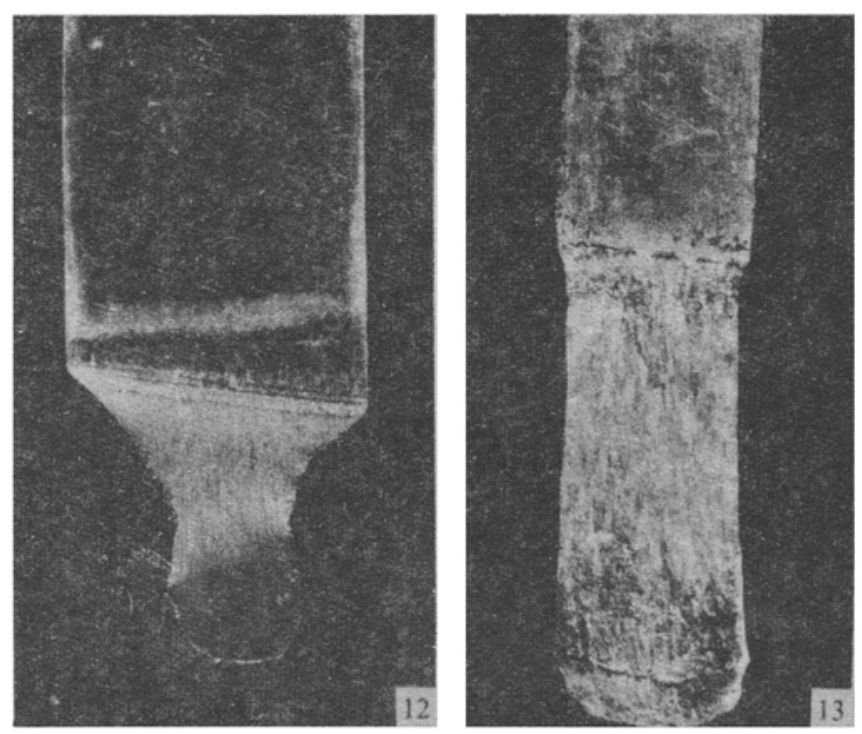

Figure 12. Appearance of gold foil anode after $95 \%$ of the foil has been dissolved potentiostatically at $+0.345 \mathrm{~V}$ ( $v \mathrm{~s} \mathrm{SCE}$ ). The surface is seen to be smooth. No necking at the solution-air interface is observed.

Figure 13. Appearance of gold foil anode after $20 \%$ of the foil has been dissolved galvanostatically at $10 \mathrm{~mA} / \mathrm{cm}^{2}$.
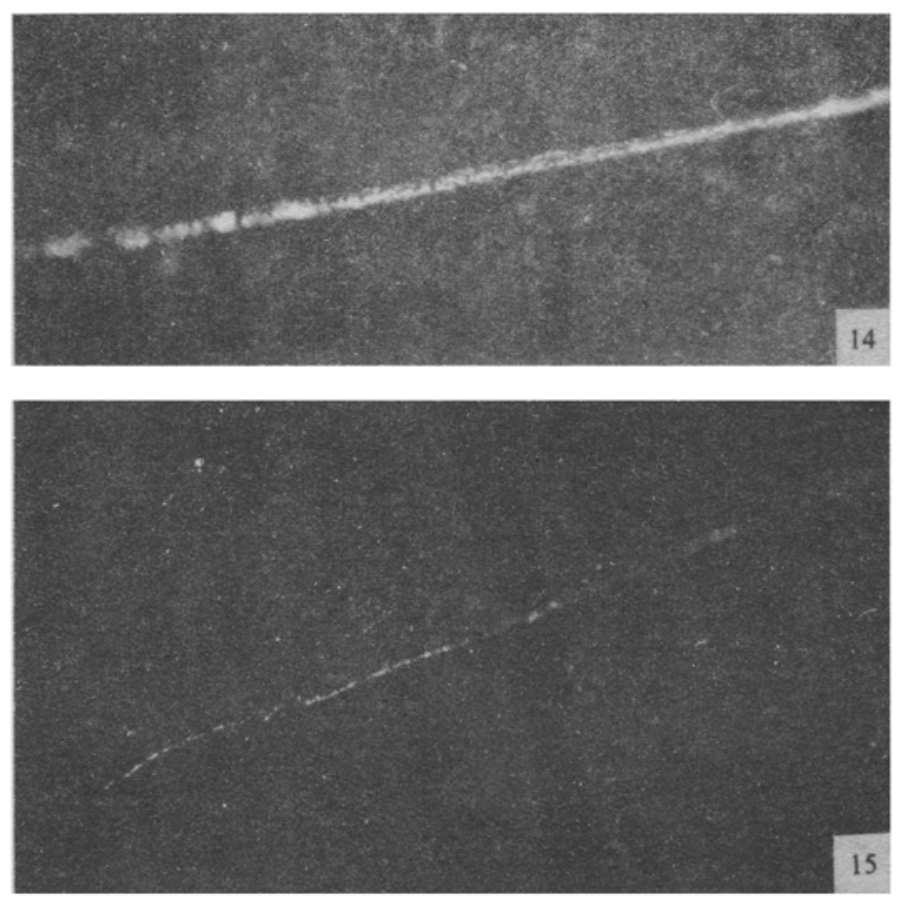

Figure 14. Cross-section of gold foil before dissolution $(\times 1)$.

Figure 15. Cross-section of gold foil after $95 \%$ of the foil has been dissolved potentiostatically at $+0-345 \mathrm{~V}$ (vS SCE) $(\times 200)$. 


\section{References}

Blum W and Hogaboom G B 1958 Principles of electroplatiny and electroforming (New York: McGraw Hill) p. 304

Britton and Dodd $1949 \mathrm{~J}$. Chem. Soc. 1835

Cathro K J and Koch F A 1964 J. Electrochem. Soc. 1111416

Fischer J and Weimer D E 1964 Precious metal plating (Teddington: Robert Draper Ltd) 107

Foulke D G 1974 Gold plating technology (eds) F H Reid and W Goldie (Scotland: Electrochemical Publications Ltd) 21

Graham Silver H 1969 J. Electrochem. Soc. 116741

Hickling A and Higgins J K 1953 Trans. Inst. Met. Finish 31274

Hoar T P and Mowat J A S 1950 Nature (London) 16564

Joshi A and Stein D F 1972 ASTM STP 499104

Joshi A, Davies L E and Palmberg P W 1975 in Methods of surface analysis (ed) Czanderna (Amsterdam: Elsevier) 213

Kirk D W and Foulkes F R 1980 J. Electrochem. Soc. 1271994

Kirk D W, Foulkes F R and Graydon W F 1978 J. Electrochem. Soc. 1251436

Kirk D W, Foulkes F R and Graydon W F 1979 J. Electrochem. Soc. 1262287

Kirk D W, Foulkes F R and Graydon W F 1980 J. Electrochem. Soc. 1271962

Kushner J B 1940 Prod. Finish p. 32

MacArthur D M 1972 J. Electrochem. Soc. 119672

Natarajan S R and Lalitha K S 1970 Met. Finishing 682

Pan P and Wan C C 1979 J. Appl. Electrochem. 9653

Thurgood C P, Kirk D W, Foulkes F R and Graydon W F 1981 J. Electrochem. Soc. 1281680

Visco R E 1974 in Modern electroplating (eds) E F A Lowerhem (New York: John Wiley) p. 225 